\title{
Intrauterine contraceptive device embedded in the omentum - case report
}

\author{
This article was published in the following Dove Press journal: \\ International Journal of Women's Health \\ I December 2015 \\ Number of times this article has been viewed
}

\section{Piotr Zolnierczyk Krzysztof Cendrowski Wlodzimierz Sawicki}

Department of Obstetrics, Gynecology and Oncology, 2nd Faculty of Medicine, Medical University of Warsaw, Warsaw, Poland
Correspondence: Piotr Zolnierczyk Department of Obstetrics, Gynecology and Oncology, 2nd Faculty of Medicine, Medical University of Warsaw, UI Kondratowicza 8, 03-242 Warsaw, Poland

Tel +48 601301773

Fax +4822326 58I8

Email pzolnier@wp.pl
Abstract: This report describes the case of a 29-year-old patient, female (nulliparous) who had an intrauterine device (IUD) inserted in 2010 and who has had no gynecological control since then (for 4 years). After this time, the asymptomatic patient had a gynecological appointment, during which a doctor did not find the strings of IUD in the speculum. Ultrasound examination did not reveal the presence of the IUD in the uterine cavity, which led to the suspicion of its presence outside the uterus. The patient was referred to a hospital, where she underwent ultrasound and X-ray examination of the pelvis that confirmed the presence of the IUD outside the uterus. Laparoscopy was performed during which the IUD was localized as being embedded in the omentum. It was removed by performing a resection of a part of the omentum with inflammatory infiltration. The patient was discharged home on the second postoperative day in a good condition. This case confirms the need for gynecological control and ultrasound examination shortly after insertion. An ultrasound or/and X-ray is mandatory in any case of absence of IUD strings previously visible in the vagina, if the patient did not observe its expulsion.

Keywords: intrauterine device, myometrium, IUD threads, uterine cavity, ultrasound examination

\section{Introduction}

According to the Central Statistical Office data, intrauterine devices (IUDs) are used by $5.5 \%$ of all women using contraception in Poland. ${ }^{1}$ This method is comfortable, comparatively inexpensive, and well tolerated by most patients. However, the IUD insertion is an invasive procedure, and the possibility of complications, sometimes even dangerous for the health of the woman, has to be taken into account. ${ }^{2-4}$ One such complication is the placement of the insert outside the uterine cavity. ${ }^{5}$ Sometimes, the IUD may be located in the cervical canal or in the uterine wall (myometrium) but there is also a risk of complete perforation of the wall of the uterus or the cervix, with the insert being located outside the uterus or migrating elsewhere, as in this case report.

\section{Case report}

The 29-year-old nulliparous patient was referred to the hospital due to the lack of visibility of IUD threads in the speculum and the suspicion of the insert having been placed outside the uterus. The patient had a relative contraindication to the use of oral contraceptives due to the history of a cerebellar stroke episode. She had an IUD inserted 4 years ago and since then underwent no gynecological or ultrasound examination. After having been referred to the hospital, the X-ray examination of the pelvis was performed, revealing the presence of the insert outside the uterine cavity (Figure 1A and B). In the ultrasound, the IUD was located above the left adnexal region, $8 \mathrm{~mm}$ from the left common iliac artery (Figure 2A). The hyperechoic structure (the insert containing barite and copper 
A

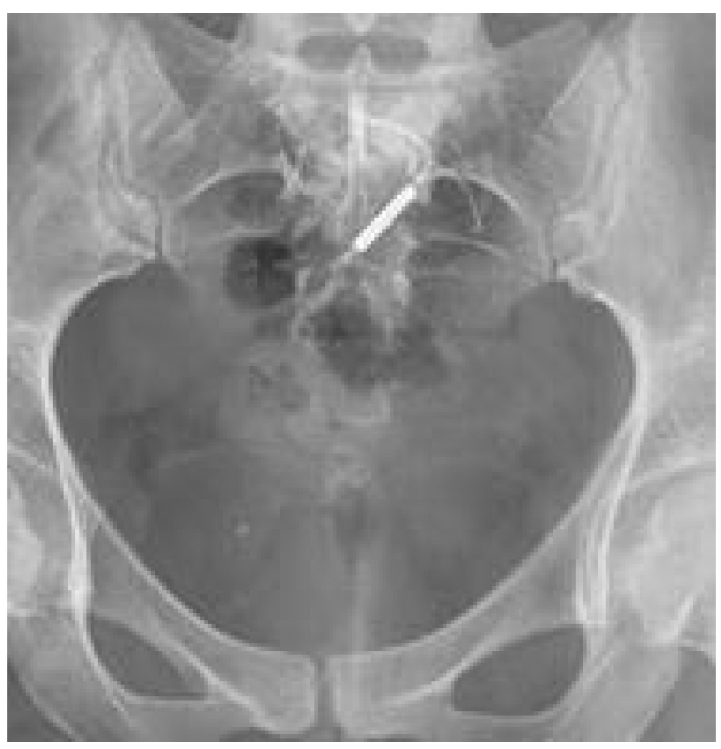

Figure I (A, B) Ectopic localization of the IUD by X-ray imaging. Abbreviation: IUD, intrauterine device.

wire) in the hypoechoic halo was visible (Figure 2B), which suggested that the IUD was encysted. The Doppler ultrasound examination revealed the increased vascularity due to foreign body reaction, particularly around the IUD ends (Figure 2C), as a result of the tissue response to the presence of the device. The ultrasound image of the changes confirmed the interstitial location of the IUD and an inflammatory reaction around it. ${ }^{6}$ The patient was referred for laparoscopy. After insertion of the optical telescope and laparoscopic instruments into the peritoneal cavity, the device itself was not visible, but an ingrown piece of an IUD thread was found on the surface of the lower part of the omentum (Figure 3). An attempt was made to remove the device by thread traction and then by traction of the isolated transverse arm of the insert (Figure 4). Both methods proved ineffective due to the strong ingrowth of the device ends into the tissue of the omentum. A cystic-like lesion surrounding the insert was also revealed (Figure 4). Therefore,
B

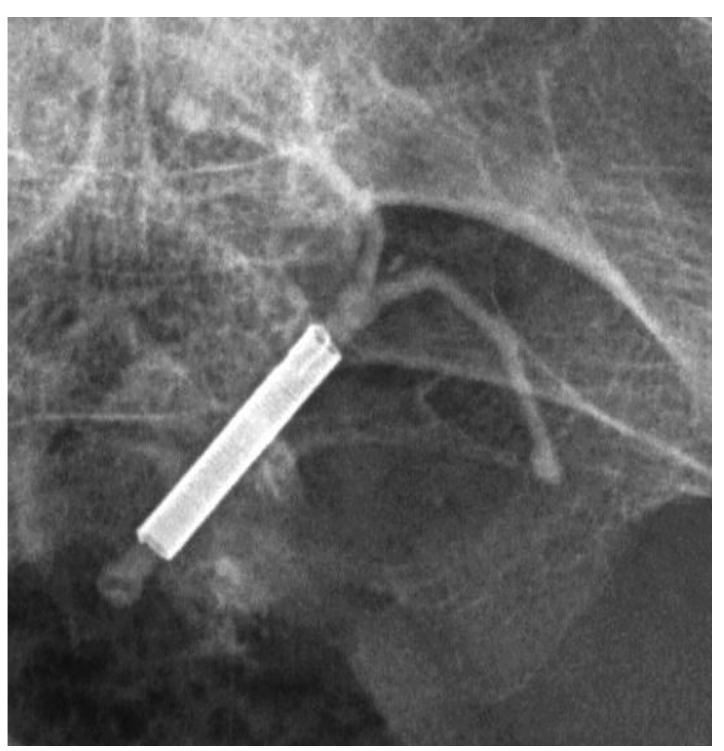

the ingrown device was removed by performing a resection of the part of the omentum with chronic inflammatory infiltration, by coagulation and cutting technique, using a bipolar forceps and scissors (Figure 5 and Figure 6). The front and the back surfaces of the uterus were carefully assessed. Accurate assessment revealed no trace of perforation in the uterine wall. Intraoperative antibiotic was administered intravenously. The postoperative course was uncomplicated, and the patient was discharged on the second day after surgery in good general condition, with no pain. The follow-up visit, scheduled 30 days after the laparoscopy, showed proper healing and no abnormalities. The histopathological examination of the obtained specimen revealed the adipose tissue of the omentum with an abundance of foci of nonspecific festering and a fibrosing granulation tissue. Approval from the Ethics Committee of the Medical University of Warsaw was not required. The patients written informed consent was obtained.
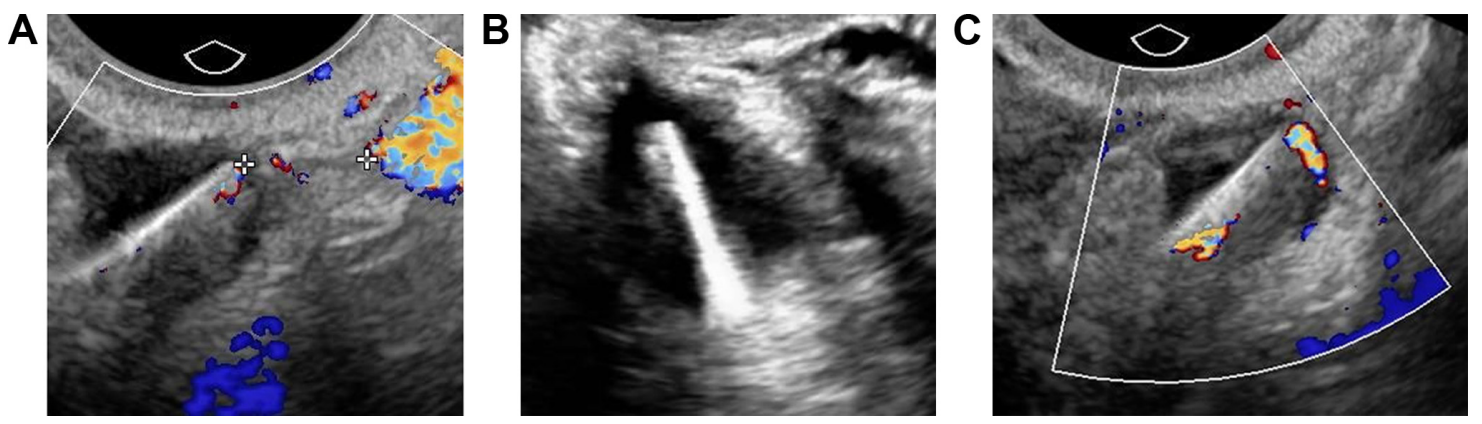

Figure 2 Ultrasound imaging of the IUD.

Notes: (A) Ectopic localization of the IUD in ultrasound imaging (8 $\mathrm{mm}$ from the left common iliac artery). (B) Ectopic localization of the IUD in ultrasound imaging. The hypoechoic halo is visible. (C) Ectopic localization of the IUD in ultrasound imaging: increased vascularity around the foreign body is visible, particularly around the IUD ends. Abbreviation: IUD, intrauterine device. 


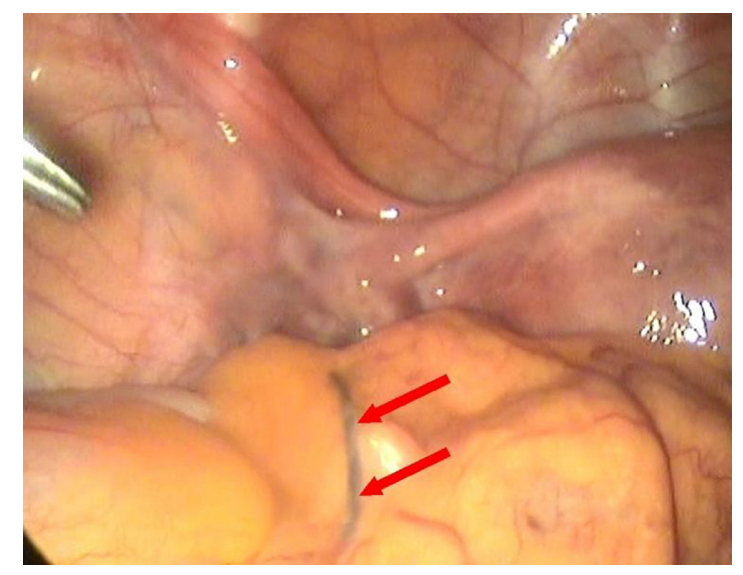

Figure 3 A piece of the IUD string (pointed with arrows) visible on the omental surface.

Abbreviation: IUD, intrauterine device.

\section{Discussion}

IUDs are usually more often introduced to multiparous than nulliparous women because of the more complicated anatomical conditions for the insertion and the potential risk of complications, such as adnexitis, which can lead to infertility through the impermeability of the fallopian tubes. ${ }^{7}$ However, it is being discussed that it may prove beneficial to use the IUDs adapted for smaller uteri in the nulliparous women, producing lower unintended pregnancy rate than in oral contraception (forgotten pill). ${ }^{8}$ In the described case, there were contraindications to the use of oral contraception due to the episode of cerebellar infarction in the patient's medical record. The insertion of an IUD is most often carried out without anesthesia or under local anesthesia only and can be associated with pain. Therefore, the pain caused by the perforation, which usually passes quickly, can remain unnoticed

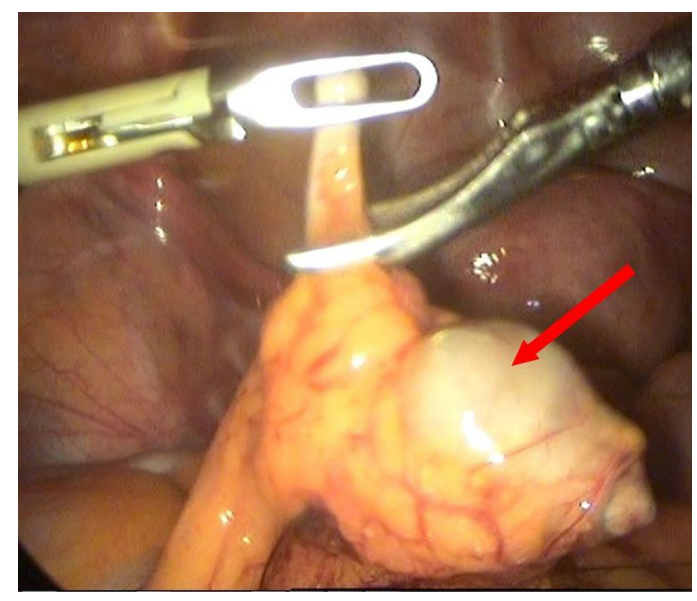

Figure 4 IUD embedded in the omentum.

Note: Encapsulation of the vertical arm of the IUD (pointed with arrow). Abbreviation: IUD, intrauterine device.

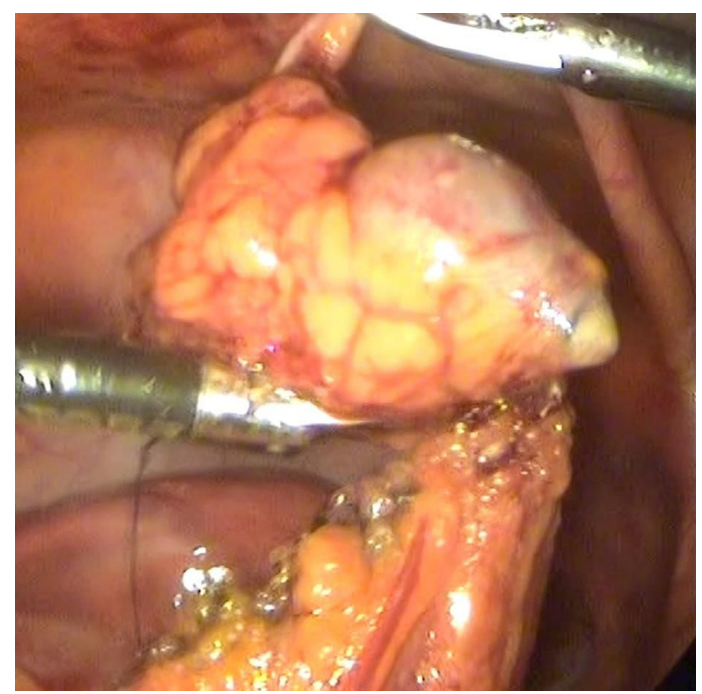

Figure 5 Bipolar electroresection of the part of the omentum with the ingrown IUD. Abbreviation: IUD, intrauterine device.

or ignored by the operator. Instrumental damage affecting the bowel or a large vessel is quickly recognized because of its significant impact on the overall condition of the patient, whereas the same perforation of the uterine wall into the peritoneal cavity usually heals by itself, may produce no clinical symptoms, and may remain unrecognized. Therefore, it is important - if only the doctor has such a possibility to perform an ultrasound examination immediately after the IUD insertion followed by a reinspection after the next menstruation or after 4-6 weeks in the absence of menstruation (insert containing levonorgestrel). Uterine perforation in connection with the insertion of the device occurs with a frequency of $\sim 1.1$ to 0.4 per 1,000 procedures ${ }^{6}$ Risk factors usually include lack of experience of the physician,

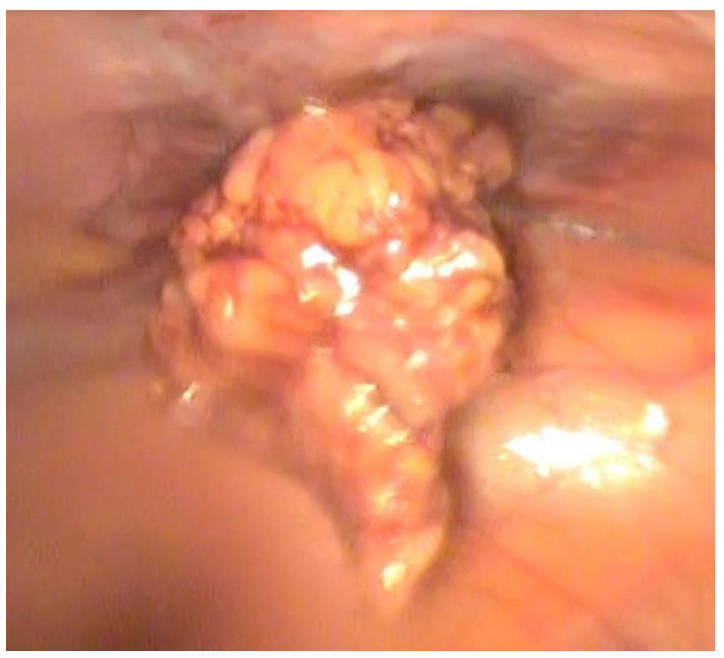

Figure 6 Removal of the IUD from the abdominal cavity. 
poor mobility of the uterus, strongly retroverted uterus, and abnormalities of the myometrium existing before or after the introduction of instruments into the uterus (uterine probe, dilators, and inserter). There are some authors, that suggest that the secondary or delayed rupture is more common and seems to be due to the spasms of the uterus. ${ }^{9}$ Other authors suggest abandoning the surgical removal of the ectopically localized device in asymptomatic patients, but there are also works confirming the possibility of serious long-term complications associated with the ectopic location of the insert. ${ }^{10,12-15}$ In view of the chronic inflammatory response of the foreign-body-type, the insert can slowly change its location, and after a few or even several years may cause damage to vital organs. Cases of its presence in the intestinal or bladder lumen have been reported. We believe, similar to most authors, that leaving a foreign body in the peritoneal cavity carries a potential risk to the health of patients. ${ }^{1-13}$ Open surgery is accompanied by worse cosmetic effect (big scar), greater risk of adhesion formations, and longer hospitalization. Laparoscopy may be the best treatment of an IUD migration because of a significantly better view, magnification, and a smaller surgical incision. ${ }^{14}$ Laparoscopy, as a minimally invasive method, which proved effective in most of such cases reported in the literature, being preceded by a precise diagnostic imaging, should be the treatment of choice. $^{15,16}$

\section{Conclusion}

This case confirms the need for gynecological examinations with ultrasound to be ordered shortly after the IUD insertion and for the performance of ultrasound and/or X-ray examinations in any case of absence of the IUD if the patient did not notice a spontaneous expulsion of the device from the uterus. It seems reasonable to encourage patients to administer self-control of the presence of the IUD threads in the vagina and to contact a doctor in the case of its absence. The surgical removal of the insert located outside the uterus appears to be necessary due to the possibility of migration, which sometimes manifests itself many years after the IUD insertion, and the associated risks for the woman's health. Laparoscopy, as a minimally invasive surgical technique, should be the first-line method of treatment in such cases.

\section{Disclosure}

The authors report no conflicts of interest in this work.

\section{References}

1. Central Statistical Office of Poland. Methods of birth control. In: The health status of the Polish population in 2009. Warsaw; 2011. Polish.

2. Gardyszewska A, Niewiadomska-Kowalczyk M, Szymanska, et al. Extrauterine mislocated IUD. Ginekol Pol. 2009;80(12):942-945.

3. Braaten KP, Benson CB, Maurer R, Goldberg AB. Malpositioned intrauterine contraceptive devices: risk factors, outcomes, and future pregnancies. Obstet Gynecol. 2011;118(5):1014-1020.

4. Derrick B, Jafri F, Saul T, et al. Perforated uterus with displacement of intrauterine device. J Emerg Med. 2013;44(6):1144-1145.

5. World Health Organization (WHO). Mechanism of Action, Safety and Efficacy of Intrauterine Devices (WHO Technical Report Series No. 753). Geneva, Switzerland: WHO; 1987:1-91.

6. Soudack M, Nachtigal A, Gaitini D. Clinically unsuspected foreign bodies: the importance of sonography. J Ultrasound Med. 2003;22(12): 1381-1385.

7. Hubacher D. Copper intrauterine device use by nulliparous women: review of side effects. Contraception. 2007;75(6):S8-S11.

8. Wildemeersch D. New intrauterine technologies for contraception and treatment in nulliparous/adolescent and parous women. Facts Views Vis Obgyn. 2009;1(3):223-232.

9. Grimaldi L, De Giorgio F, Andreotta P, D’Alessio MC, Piscicelli C, Pascali VL. Medicolegal aspects of an unusual uterine perforation with multiload-Cu 375R. Am J Forensic Med Pathol. 2005;26:365-366.

10. Harrison-Woolrych M, Ashton J, Coulter D. Uterine perforation on intrauterine insertion: is the incidence higher than previously reported? Contraception. 2003;67:53-56.

11. Kaislasuo J, Suhonen S, Gissler M, et al. Uterine perforation caused by intrauterine devices: clinical course and treatment. Hum Reprod. 2013; 28(6): 1546 .

12. Mahmutyazicioglu K, Ozdemir H, Ozkan P. Migration of an intrauterine contraceptive device to the urinary bladder: sonographic findings. J Clin Ultrasound. 2002;30:496-498.

13. Inceboz US, Özçakir HT, Uyar Y, et al. Migration of an intrauterine contraceptive device to the sigmoid colon: a case report. Eur J Contracept Reprod Health Care. 2003;8:229-232.

14. Sharifiaghdas F, Beigi FM, Abdi H. Laparoscopic removal of a migrated intrauterine device. Urol J. 2007;4:177-179.

15. Swati D, Ghanouni P, Jeffrey RB. Early sonographic diagnosis of intrauterine device migration to the adnexa. J Clin Ultrasound. 2009; 37:414-416.

16. Boortz HE, Margolis DJ, Ragavendra N, Patel MK, Kadell BM. Migration of intrauterine devices: radiologic findings and implications for patient care. Radiographics. 2012;32(2):335-352.
International Journal of Women's Health

\section{Publish your work in this journal}

The International Journal of Women's Health is an international, peerreviewed open-access journal publishing original research, reports, editorials, reviews and commentaries on all aspects of women's healthcare including gynecology, obstetrics, and breast cancer. The manuscript management system is completely online and includes

\section{Dovepress}

a very quick and fair peer-review system, which is all easy to use. Visit http://www.dovepress.com/testimonials.php to read real quotes from published authors. 